\title{
Combining Time and Physical Workload Analysis on Cold Press Working Group for Operator Management in Manufacturing Company
}

\author{
Muhammad Ragil Suryoputro ${ }^{1}$, Tresna Candra Ginanjar ${ }^{1}$, Amarria Dila Sari ${ }^{1}$ \\ ${ }^{1}$ Industrial Engineering Deparment, Faculty of Industrial Technology, Islamic University of Indonesia, Jl. Kaliurang km 14.5, Yogyakarta \\ Indonesia
}

\begin{abstract}
Efficiency improvement in manufacturing company is essential to ensure the cycle of continuous improvement. Prior decision was reducing 6 operators in the cold press team work into 5 workers. Thus significant changes, of course, would resulted in the change of the workload experienced by each operator. The research objective in this study is validating from the productivity of the reduction conducted by measuring the workload with combining Full Time Equivalent (FTE) and Cardiovascular Load Percentage (\%CVL). The result states that there are differences in measurement results workload from both methods. Based on the FTE method, all Cold Press operator's workload has an index in average of 1.4128 with all was above 1.28 indicating the "Overload" condition. On the other hand, based on the physical workload method obtained that \% CVL in average was $8.272 \%$ with all operator was below 30\% which indicates the workload of all Cold Press operators were in a not experiencing fatigue category. Keywords: Workload, FTE, \%CVL, productivity, Physical Workload.
\end{abstract}

\section{Introduction}

XYZ Manufacturing company is a manufacturing company that are producing musical instrument that located in the main production area in Indonesia. Based on previous pilot study for this manufacturing company, in order to improve productivity on a production line, the Cold Press working group control labour efficiency by reducing the number of operators from the original 6 operators into 5 operators. Determination of the amount is based on a pilot workload analysis. In its production activities that were divided into several working groups that have different kinds of production depending on the production process, the type of musical instrument, and what kind of cabinet in the process. For each working group in XYZ Company provides a Value Stream Mapping and Industrial Engineering project, where each working group is targeted to perform labour productivity increases of up to $15 \%$ for the cabinet or products assembly and $30 \%$ for the cabinet or non-assembly products, supported by the application of Kaizen in each working group. The Cold Press working group is one group of non-assembly work in XYZ Company, which has run the project. In order to increase the productivity of the Cold Press working group production control labour efficiency by reducing the number of operators from the original 6 carriers to 5 operators.

Every worker in a company must have a workload. The workload can be defined as the price or value of the achievement on the target activity [1]. If this value is too high from the job performed, the fatigue level is also high.
Fatigue will reduce performance and increase the error rate. Increased faulty work will provide greater opportunities for work accidents [2].

There were researches regarding the workload using various methods in companies, NASA TLX (Task Load Index) for mental workload analysis [3] and [4]; WISN (Workload Indicators of Staffing Needs) for wellbeing of household, medical staff [5], and Namibia [6]; Cardio Vascular Load Method for physical workload [7] and Stopwatch method in standard time measurement for time based workload analysis [8].

With the change of the number of operators in the working group Cold Press, of course, will change the workload perceived by each operator. This study will conduct research on methods of measuring the workload with Full Time Equivalent and Percentage CVL, continued with a comparison of the results of the two methods. The determination of these two methods is based as a link between the type of work and the time of the type of work performed by the operator. In general, most types of work performed by the operator in the Cold Press working group is physical workload types such as lifting the cabinet, push the cabinet, and also cut the cabinet in various types, sizes and weights. Furthermore, every job in the Cold Press working group each cabinet has a cycle time, for example the time required to process a single cabinet. This shows the necessity of understanding the difference in the type of workload measurement results based on the method of Full Time Equivalent (FTE)-time workload measurement and the method of percentage of CVL-physical workload 
measurement. So the final result of this study is expected to be known to the workload perceived by each operator based on time and physical workload, and also the correlation based on both methods.

\section{Methods}

\subsection{Research subject}

In this study sampling was conducted using purposive sampling technique. The study was performed on the woodworking department, especially focused on the Cold Press working group that meets the criteria specified. The criteria used to select the sample is as follows. The first is good mental and physical health during the data retrieval process, continued with male operator targeted. The age range was between 20 and 35 years old. In addition, the operator should understand the production process and the occupational safety and health requirements

\subsection{Research Procedure}

Workload analysis was conducted using two stages of measurement and one stage of qualitative interpretation. There were three guideline defined to conduct the study, FTE calculation, \%CVL calculation and consultation of combination results from both criteria. Procedure in performing workload analysis in this research were divided into three stages:

a. Full Time Equivavlent (FTE) Stage: The FTE was the beginning step in conducting the research. FTE was performed to simplify the work measurement by converting hours' workload into the number of workers needed to completing the task/job required [9]. There were three types of the implication on FTE score, Overload (>1.28), Normal (1-1.28) and Underload (>1) [10]. There were five steps to measuring the FTE score: measuring allowance and effective time calculation, adequacy test and data uniformity, adjustment rating factor, normal time and standard time calculation, and full time equivalent measurement.

b. Cardiovascular Load Percentage (\%CVL): Meanwhile, \%CVL was conducted by examining the physical workload using cardiovascular load with four distinctive results, acceptable level $(<30 \%)$, moderate level (30\%-59\%), high level (60\%-99\%) and intolerable high level (100\%) [11]. The physical workload measured the working and rest pulse rate by the help of stopwatch. The pulse rate was used to indicate the workload and calculated the \%CVL. this stage will be determined allowance consisting of leniency for personal needs, allowance to eliminate the sense of fatique, allowance for inevitable obstacles and work environment. c. Consultation of combination results from both criteria: Both criteria were analysed and consulted with the management to understand the nature of the result, and recommend the further action needed. At this stage will be determined the effectiveness on the measurement of time base workload and physical workload.

\section{Results and Discussion}

Cold press working group was in the wood working area that performing 27 cabinets and 17 models that would be distributed across sections. The job description involved in this group were veneer cut, panel saw, chipping, glue spreader, press machine, bench saw, and key bed bone assembly. There were 5 operators with age range from 22-33 years old as the respondents.

This study conducted based on company's data on June to August 2017. Operators work hours were from 07.00 until 16.00 on working days (5 days a week, Monday to Friday).

\subsection{Full Time Equivalent}

The Full Time Equivalent (FTE) was calculated based on the job description performed for each operator. The job description then would be measured for each working element attached. After the working hours were accumulated for each operator and each working element, this cycle time was then multiplied by the rating factor and allowance to get the normal time and standard time accordingly. As the example, the panel saw for Side Board B1 model, the working time was 0.39 minutes. The calculation of rating factor and allowance were displayed based on the table 1 and table 2 respectively.

Table 1. Rating Factor

\begin{tabular}{|l|c|c|c|}
\hline Factors & Category & Score & Accumulation \\
\hline Skill & Superskill (A2) & 0.13 & \\
\cline { 1 - 2 } Effort & Good (C1) & 0.05 & \\
\hline $\begin{array}{l}\text { Conditi } \\
\text { on }\end{array}$ & Fair (E) & -0.03 & \\
\cline { 1 - 1 } $\begin{array}{l}\text { Consist } \\
\text { ency }\end{array}$ & Good (C) & 0.01 & 0.16 \\
\hline \multicolumn{2}{|c|}{1.16} \\
\hline
\end{tabular}

Table 2. Allowance

\begin{tabular}{|l|l|c|}
\hline \multicolumn{1}{|c|}{ Factors } & \multicolumn{1}{|c|}{ Category } & Percentage \\
\hline Work performed & Light & $7.5 \%$ \\
\hline Work Attitude & Stand on both feet & $1.5 \%$ \\
\hline Work Movement & $\begin{array}{l}\text { Swing restricted on } \\
\text { hammers }\end{array}$ & $1.0 \%$ \\
\hline Eye fatigue & Disjointed views & $1.0 \%$ \\
\hline Temperature & Normal & $5.0 \%$ \\
\hline Atmosphere & Enough & $2.0 \%$ \\
\hline Environment & $\begin{array}{l}\text { Repeated circle per 5- } \\
10 \text { seconds }\end{array}$ & $2.0 \%$ \\
\hline Personal Allowance & Male & $1.0 \%$ \\
\hline
\end{tabular}




\begin{tabular}{|c|c|}
\hline Total Allowance & $21.0 \%$ \\
\hline Total Efficiency Factor & $79.0 \%$ \\
\hline
\end{tabular}

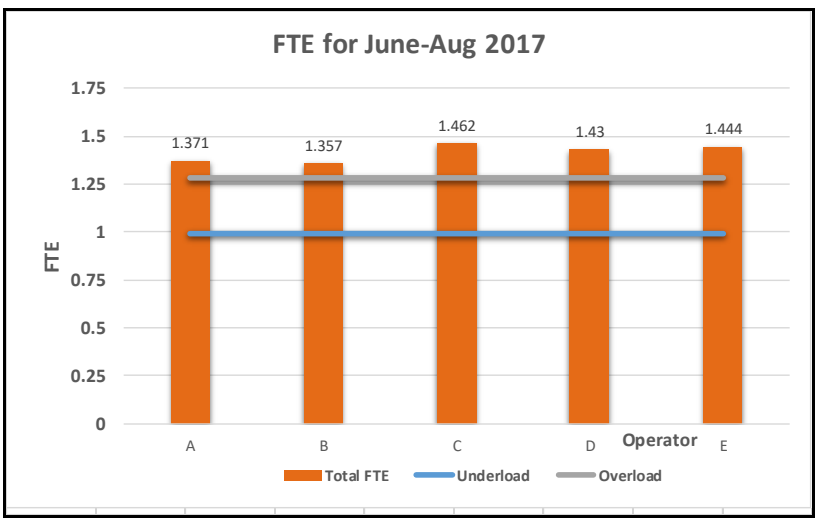

Figure 1. FTE for June-August 2017

Based on the calculation using the rating factor, the normal time for the Panel Saw of the Side Board B1 (average time was 0.39 minutes) would be 0.4524 minutes. In addition, the standard time would be calculated as 0.58 minutes. Based on the frequency observed was 32 times a day, the FTE calculated was 0.0493 . Continued by all element and all operator, the complete list for the FTE for all operator was captured in the Figure 1.

The figure 1 shows that all the operator were burdened with overload works due to the FTE all above 1.28. This problem could be solved by adding working hours (overtime) or adding operator (this was unlikely chosen by the company). High FTE index gained by every Cold Press operator was influenced by several factors including production planning and allowance granted. In this study allowance was given quite high at $21 \%$. There were several categories in the allowance could be improved so as to reduce the percentage of allowance. One of the high factors was the environmental factor with the percentage of 5\%. This was due to the temperature of the working environment are included in the normal category but still make the operator feel stifling in occasionally. The impact observed was sometimes the operator tried to find a fresh spot for refreshing the body. In addition, atmospheric factors also influenced the allowance in this study. Allowance in the amount of $2 \%$ included in the category enough because in the Cold Press working environment, the ventilation was categorized as good but still there was the smell - quite annoying odours such as the smell of Kony Bond glue.

\subsection{Cardiovascular Load Percentage}

The data required in the measurement of the cardiovascular load percentage (\% CVL) as physical workload were data of working pulse, resting pulse rate, and age of each operator. The pulse data obtained by measuring the time of 10 pulse rate both worked and rested on operator using a stopwatch. Based on the working hours implemented by the company, the pulse rates were collected during 5 working pulse $(09.00,10.00$, $11.00,12.00$ and 14.00) and 2 resting pulse (09.30 and 12.30). On each operator, the observations/measurements were conducted on this 7 times pulse rate on 4 working days and calculated for the average results. The data for the pulse rate shown in the table 3.

Table 3. Pulse Rate Operator

\begin{tabular}{|c|c|c|c|c|c|}
\hline \multirow{2}{*}{ Operator } & \multirow{2}{*}{ Age } & \multicolumn{2}{|c|}{$\begin{array}{c}\text { Average Time } \\
\text { for 10 Pulse }\end{array}$} & \multicolumn{2}{c|}{ Pulse Rate } \\
\cline { 3 - 6 } & & Rest & Work & Rest & Work \\
\hline A & 33 & 6.91 & 6.66 & 86.81 & 90.10 \\
\hline B & 29 & 7.65 & 6.56 & 78.41 & 91.43 \\
\hline C & 23 & 7.69 & 6.95 & 77.97 & 86.34 \\
\hline D & 23 & 7.42 & 6.54 & 80.88 & 91.81 \\
\hline E & 22 & 7.49 & 6.52 & 80.22 & 92.06 \\
\hline
\end{tabular}

Cardiovascular strain was an estimation to determine the classification of the workload by increased pulse rate of work from the resting pulse compared with the maximum pulse rate. The following shown figure 2 as the recapitulation of the calculation workload in the Cold Press.

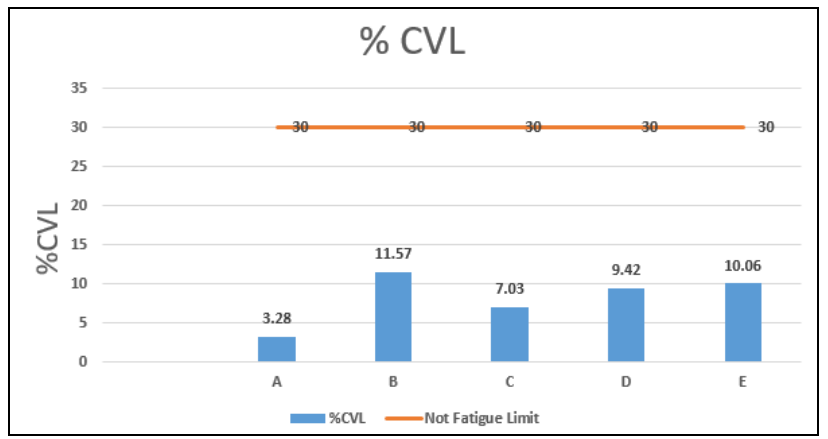

Figure 2. \% CVL calculation result

Based on the results of the calculation of the workload for example for the type of work on the operator A aged 33 years with the job type was cutting in the machine panel saw, cut the cabinet key bed P22 or U1J in engine bench saw, and the process of cutting $\mathrm{R}$ in the machine chipping the category in the classification of the workload is not experiencing fatigue. This was because the percentage of operator A CVL was 3.28 (\% CVL<30\%).

From the workload classification by methods Cardiovascular Load in all sections Cold Press operator had the load of Cardiovascular below 30\%. So that the operator workload could be included in the classification did not experience fatigue. The least load of cardiovascular was in a operator that had a lowest percentage of the cardiovascular load $(3: 28 \%)$ with a job description focuses on the cutting process in the machine cabinet Panel Saw. The greatest burden by operator B was equal to $11: 57 \%$. the job description was in part the emphasis, gluing and assembling bone Key Bed and U1J P22 models.

\subsection{Combination results from both criteria}


Based on the results above occurred differences in the results of the two methods of measuring the workload. For the method of Full Time Equivalent all operators at the Cold Press had excessive workloads. This could be caused by several factors such as the length of time of execution of each process per cabinet, the high allowance, many types of cabinet are processed, until the layout is not optimal. While based on the measurement on \%CVL workload results obtained that all operator of Cold Press had \% CVL below 30\%, which indicated that all operators were in a state of not experiencing fatigue. However, there were still some works continued to be performed could pose a potential danger to health and safety. This result was because the workload measurement method used has a different approach. The first method is the measurement of the workload with the method of Full Time Equivalent (FTE) was a measurement of workload by using the approach of working time as a reference. The second method was by the percentage of CVL was measuring the level of physical workloads that require physical energy muscle as a source of energy. From the measurement results of both methods occurred differences in measurement results workload by both methods could be concluded that operator did not experience fatigue physically but operators are in an overload time measured or the operator could still receive excessive workloads FTE based on the calculation method. Based on data from the efficiency of June 2017 there were 5 working days from 15 effective days were overtime work and in July 2017 there were 12 days of overtime of 21 effective working days.

Taking into further account the results of the FTE workload measurement method and the percentage CVL researchers were also trying to find the best alternative between the two methods was based on salary costs incurred. Based on the comparison calculation resulting costs to be paid in the period of September 2017 November 2017, doing overtime would have 1.5 times more expensive than the cost of the salary increase of the operator. Whereas, if only the company add one more operator, the cost incurred 0.7 times cheaper than by doing overtime. This was merely by the salary and fees only, excluding the long consideration of hire and termination contract, and other cost derived by adding or reducing number of operator.

\section{Conclusion}

Based on the research, could be concluded that all operator was categorized on FTE as overload, all operator was categorized on \%CVL as not experiencing fatigue, and also the correlation between both categories did not state equal comparison. Therefore, it validated on the increased productivity (based on the increased FTE score) even though the physical workload was perceived below the limit (underload) as the research objectives. Regarding the FTE method, the workload experienced by all Cold Press operators were above 1.28 (indication of the "Overload" condition) as 1.371, 1.357, 1.462, 1.43 and 1.444 respectively resulted in average 1.4128 . In the contrary, based on \% CVL method, the physical workload perceived as non-experiencing fatigue category due to the average score was $8.272 \%$ and all score were below $30 \%$ (even less than $12 \%$ ).

\section{References}

[1] Hart, S.G. "NASA Task Load Index (NASA-TLX): 20 Years Later", Moffett Field: NASA-Ames Research Center (1990)

[2] Nurmianto, E. Ergonomi: Konsep Dasar dan Aplikasinya. Surabaya: Prima Printing. (2004).

[3] EH. Puspawardhani, MR. Suryoputro, AD. Sari, RD. Kurnia, and H. Purnomo. Mental workload analysis using NASA-TLX method between various level of work in plastic injection division of manufacturing company. Advances in Intelligent Systems and Computing Advances in Safety Management and Human Factors, Orlando (2016)

[4] O. J. Sealetsa and A. Thatcher. Ergonomics issues among sewing machine operators in the textile manufacturing industry in Botswana. Work, 38, pp. 279-289 (2011)

[5] D. Bonfim, A.M Laus, A.E Leal, F.M.T Fugulin, R.R Gaidzinski. Application of the Workload Indicators of Staffing Need method to predict nursing human resources at a Family Health Service. Revista Latino-Americana de Enfermagem, 24 (2016)

[6] P.A McQuid, R.L Kolehmainen-Aitken, and N. Forster. Applying the workload indicators of staffing need (WISN) method in Namibia: challenges and implications for human resources for health policy. Human Resources for Health, 11, 64 (2013)

[7] A.D Sari, M.R. Suryoputro, M.D. Pramaningtyas, P.S Putra and S.B. Maulidyawati. Work Physiology Evaluation of Laundry Workers. IOP Conference Series: Materials Science and Engineering (2016)

[8] H. Purnomo. Workload Analysis For Determining The Number Of Employees At Bank Companies. GEMA Jurnal 201. 2068-2076(2015)

[9] Zimmerman, S., Gruber-Baldini, A. L., Hebel, J. R., Sloane, P. D., \& Magaziner, J. (2002). Nursing home facility risk factors for infection and hospitalization: importance of registered nurse turnover, administration, and social factors. Journal of the American Geriatrics Society, 50(12), 1987 1995.

[10] Tridoyo, T., \& Sriyanto, S. Analisis Beban Kerja Dengan Metode Full Time Equivalent Untuk Mengoptimalkan Kinerja Karyawan Pada Pt Astra International Tbk-Honda Sales Operation Region Semarang. Industrial Engineering Online Journal, 3(2). (2014)

[11] Ismaila, S. O., Oriolowo, K. T., \& Akanbi, O. G. Cardiovascular strain of sawmill workers in SouthWestern Nigeria. International Journal of Occupational Safety and Ergonomics, 19(4), 607611. (2013). 